\title{
A comparison between cut and intensively grazed swards on DM yield of perennial ryegrass
}

\section{Wims ${ }^{1,2}$, M McEvoy ${ }^{1}$, T Boland ${ }^{2}$, M O'Donovan ${ }^{1}$}

${ }^{1}$ Moorepark Dairy Production Research Centre, Fermoy, Co Cork, Ireland

${ }^{2}$ School of Agriculture, Food Science and Veterinary Medicine, NUI Dublin, Belfield, Dublin 4, Ireland

Email:cathal.wims@teagasc.ie

Introduction Grassland is of major importance to Irish agriculture due to our reliance on grazed grass and grass silage as the base feeds for livestock production. To achieve the optimum performance from a grass ley the most appropriate grass variety must be selected while considering the target production system and soil type with individual variety performance dependant on species, ploidy and production traits. Different cultivar evaluation protocols are employed throughout Ireland and Europe, and testing is generally conducted under cutting management practices. The protocols employed can generally be segregated into simulated grazing or conservation based cutting regimes, with some integrating both conservation and grazing. Wims et al., (2009) reported that grass cultivars re-rank between simulated grazing and conservation based cutting regimes. However mechanical defoliation of cultivars may not be directly comparable to animal grazing in terms of dry matter (DM) production. The objective of this study was to compare the total DM and seasonal DM production of cultivars managed under either animal grazing or simulated grazing and to evaluate the effect of incorporating a silage harvest into these managements on total and seasonal DM production.

Material and methods Four managements were employed as follows:

i) Animal Grazing (AG) (300 kg N/ha) incorporating 10 animal grazing rotations from February to November ( $\mathrm{n}=60)$;

ii) Simulated Grazing (SG) (350kg N/ha) incorporating 10 mechanical defoliations from February to November $(\mathrm{n}=60)$;

iii) One-Cut Silage and AG (300 kg N/ha) incorporating 7 animal grazing rotations from February to November with silage harvested in late May $(\mathrm{n}=30)$;

iv) Simulated One-Cut Silage (335kg N/ha) incorporating 8 mechanical defoliations from February to November with silage harvested in late May $(\mathrm{n}=30)$;

Managements were either classified as AG (Managements i and iii) or as SG (Managements ii and iv). Ten cultivars were assessed across the four managements with three replicates per cultivar for each management. The cultivars used were Abermagic, Aberstar, Astonenergy, Dunluce, Magician, Millenium, Navan, Spelga, Twystar and Tyrella. All plots were harvested with an Etisa mower and fertiliser was applied within two days of defoliation. A $1.5 \mathrm{~m}$ wide strip was cut from the AG plots with the remainder of the plot grazed with dairy cows. All dung pads were removed after each grazing. Within each management the overall grazing season was divided into spring (harvests between February $1^{\text {st }}$ and April $10^{\text {th }}$ ), summer (harvests between April $11^{\text {th }}$ and August $6^{\text {th }}$ ) and autumn (harvests from August $7^{\text {th }}$ onwards). All data were analysed using analysis of variance in SAS. Cultivar, management and the effect of silage harvest were included in the model. Interactions were tested for and none were found so interactions were excluded in the final analysis.

Results Cultivar and management had a significant effect $(\mathrm{P}<0.05)$ on both seasonal DM yield and total DM yield. The SG managements yielded $13.2 \mathrm{t} \mathrm{DM} /$ ha (s.d. 1393.3) which was significantly $(\mathrm{P}<0.001)$ higher than the AG managements yielding $10.2 \mathrm{t} \mathrm{DM} / \mathrm{ha}$ (s.d. 1474.6). In the autumn period management had a significant effect $(\mathrm{P}<0.001)$ on $\mathrm{DM}$ yield, the difference between managements was $167 \mathrm{~kg} \mathrm{DM} / \mathrm{ha}$ and this is not considered to be biologically significant. Silage harvest also had a significant effect $(\mathrm{P}<0.001)$ on total DM yield, summer DM yield and autumn DM yield but not on spring DM yield, as there was no difference in harvest strategy during the spring period. Silage harvest had a significant effect $(\mathrm{P}<0.001)$ on autumn DM yield, however this difference of $175 \mathrm{~kg} \mathrm{DM} / \mathrm{ha}$ is not considered to be biologically different. Managements that incorporated a silage harvest yielded $12.8 \mathrm{t} \mathrm{DM} / \mathrm{ha}$ (s.d. 1721.8) which was $18.0 \%$ higher than managements without a silage harvest.

Table 1 Effect of grass cultivar evaluation management and integration of silage harvest on seasonal and total DM production

\begin{tabular}{llllllll}
\hline \hline & \multirow{2}{*}{ AG } & SG & $\begin{array}{l}\text { Silage } \\
\text { Harvest }\end{array}$ & $\begin{array}{l}\text { No Silage } \\
\text { Harvest }\end{array}$ & Management & Silage & SED \\
\hline Spring DM Yield (kg DM/ha) & 1515 & 1998 & 1772 & 1741 & $\mathrm{P}<0.001$ & N.S. & 59.69 \\
Summer DM Yield (kg DM/ha) & 5787 & 8446 & 8140 & 6093 & $\mathrm{P}<0.001$ & $\mathrm{P}<0.001$ & 150.71 \\
Autumn DM Yield (kg DM/ha) & 2884 & 2717 & 2888 & 2713 & $\mathrm{P}<0.001$ & $\mathrm{P}<0.001$ & 72.27 \\
Total DM Yield (kg DM/ha) & 10185 & 13161 & 12800 & 10546 & $\mathrm{P}<0.001$ & $\mathrm{P}<0.001$ & 222.61 \\
\hline \hline
\end{tabular}

Conclusion Cultivars evaluated under simulated grazing had higher DM yields than cultivars evaluated under animal grazing. However as no interaction was found between cultivar and management, it indicates that simulated grazing is representative of the relative performance of a cultivar under animal grazing.

\section{References}

Wims, C., Kennedy, E., Boland, T., and O’Donovan, M. 2009 Agricultural Research Forum, Ireland. 35, 136 